\title{
Cilium-autonomous regulation of tubulin transport by IFT
}

\author{
K Lechtreck \\ From Cilia 2014 - Second International Conference \\ Paris, France. 18-21 November 2014
}

\section{Objective}

The assembly of the axoneme, the structural scaffold of cilia and flagella, requires translocation of a vast quantity of tubulin into the growing cilium, but the mechanisms that regulate the targeting, quantity, and timing of tubulin transport are largely unknown.

\section{Methods}

GFP-tagged $\alpha$-tubulin was expressed in Chlamydomonas reinhardtii and its transport in cilia was analyzed using TIRF microscopy.

\section{Results}

GFP-tagged $\alpha$-tubulin entered Chlamydomonas cilia as a cargo of IFT and by diffusion. IFT-based transport of GFP-tubulin occurred at a low frequency in full-length steady-state cilia and was strongly increased during ciliary growth when IFT trains carried more tubulin. Cells possessing both non-growing and growing cilia selectively targeted GFP-tubulin into the latter indicating that cells regulate tubulin influx individually for each cilium. The preferential delivery of tubulin boosted the concentration of soluble tubulin in the matrix of growing cilia. Cilia length mutants showed abnormal kinetics of tubulin transport, suggesting that ciliary length control involves a regulation of the occupancy of IFT trains by tubulin cargoes.

\section{Conclusions}

Tubulin is a bona fide cargo of IFT. We propose that IFT functions as a tubulin pump concentrating soluble tubulin in growing cilia which promotes the elongation of the axonemal microtubules and ciliary growth.

Cellular Biology, University of Georgia, Athens, GA, USA
Published: 13 July 2015

doi:10.1186/2046-2530-4-S1-08

Cite this article as: Lechtreck: Cilium-autonomous regulation of tubulin transport by IFT. Cilia 2015 4(Suppl 1):08.
Submit your next manuscript to BioMed Central and take full advantage of:

- Convenient online submission

- Thorough peer review

- No space constraints or color figure charges

- Immediate publication on acceptance

- Inclusion in PubMed, CAS, Scopus and Google Scholar

- Research which is freely available for redistribution 